\title{
Gerilim Sensörü Uygulamaları İçin Çok Duvarlı Karbon Nanotüp Dolgulu Elastomer Nanokompozitlerin Piezodirenç Özelliklerinin Araştırılması
}

\author{
Hasan Kasım ${ }^{1 *}$ \\ 1* Emsa Nano Teknoloji Enerji San. ve Tic. A.Ş., R\&D Bölümü, Bursa, Türkiye, (ORCID: 0000-0002-3024-5207), hasankasim@emsaglobal.com
}

(İlk Geliş Tarihi 14 Nisan 2021 ve Kabul Tarihi 27 Haziran 2021)

(DOI: 10.31590/ejosat.915899)

ATIF/REFERENCE: Kasım, H. (2021). Gerilim Sensörü Uygulamaları İçin Çok Duvarlı Karbon Nanotüp Dolgulu Elastomer Nanokompozitlerin Piezodirenç Özelliklerinin Araştırılması. Avrupa Bilim ve Teknoloji Dergisi, (25), 370-379.

Öz

Elastomer matris ve çok duvarlı karbon nanotüp (MW-CNT) dolgu malzemeleri ile hazırlanan nanokompozitlerin piezodirenç değişimine göre gerilme sensörü olarak kullanılma olasılı̆ğ araştırılmıştır. Farklı konsantrasyonlar da MW-CNT ile doldurulmuş elastomer esaslı nanokompozitlerin deformasyon davranışlarını belirlemek için piezodirenç mekanizmasının sistematik bir çalışması gerçekleştirilmiştir. Hazırlanan numunelerin serbest halde iletkenlikleri ölçülmüş ve süzülme eşiğini işaret eden kritik dolgu miktar aralığı tespit edilmiştir. Nanokompozit numunelerine uygulanan gerilmeye bağlı uzamaların neden olduğu direnç değişiklikleri, sırasıyla doğrusal ve doğrusal olmayan iki farklı bölgede piezo davranış göstermiştir. Direnç değişikliğinden, uygulanan gerilmeye bağlı uzamanın bir fonksiyonu olarak hesaplanan ölçüm faktörü, doğrusal bölge için yaklaşık 90 ve doğrusal olmayan bölge için 270 olarak ölçülmüştür. Ağıllıkça \%2,92 oranında MW-CNT dolgulu nanokompozitler, $\% 90$ ve $\% 150$ uzamalar ile yapılan tekrarlı yükleme testlerinde tekrarlana bilirlik ve mükemmel geriye dönüş performansı göstermiş̧ir. $\mathrm{Bu}$ çalışma, elastomer malzemelere uygun oranlarda MW-CNT'ler ekleyerek piezodirenç özellikler kazandırdıklarını ve yüksek uzama gerektiren dinamik çalışma ortamlarında hassas gerilim sensörleri olarak kullanılabileceğini göstermiştir.

Anahtar Kelimeler: Karbon Nanotüp, Piezodirençlilik, Elastomerler, Gerilim Sensörü, Elektriksel İletkenlik.

\section{Investigation of Piezoresistive Properties of Multi-walled Carbon Nanotube Filled Elastomer Nanocomposites for Strain Sensor Application}

\begin{abstract}
The possibility of using nanocomposites prepared with elastomer matrix and multi-walled carbon nanotube (MW-CNT) filler materials as a strain sensor according to the change of piezoresistance was investigated. A systematic study of the piezoresistive mechanism was realized to determine the deformation behavior of elastomer nanocomposites filled with MW-CNT at different concentrations. By measuring the prepared samples' free-state electrical conductivity, the critical filler material amount range indicating the percolation threshold was determined. The resistance changes caused by strains due to the stress applied to nanocomposite specimens showed piezo behavior in two different regions, linear and nonlinear, respectively. The gauge factor found using the change of resistance as a function of the strain was measured as approximately 90 for the linear region and 270 for the nonlinear region. MW-CNT filled nanocomposites with a ratio of $2.92 \%$ by weight showed reproducibility and excellent recovery performance in cyclic loading tests with $90 \%$ and $150 \%$ strains. This study showed that by adding MW-CNTs to elastomer materials in optimum proportions, they gain piezoresistive properties and could be used as sensitive strain sensors in dynamic working environments that require high elongation.
\end{abstract}

Keywords: Carbon Nanotube, Piezoresistivity, Elastomers, Strain Sensors, Electrical Conductivity.

*Sorumlu Yazar: manager@emsaglobal.com 


\section{Giriş}

Mekanik zorlamanın etkisi altındaki yapısal değişikliklerin bir sonucu olarak direnci değişen dolgu malzemeleri ile hazırlanan polimer esaslı nanokompozit malzemeler, mekanik hasarların tespitinde ve malzemeler üzerinde oluşan gerilmelerin tespitinde piezodirençli sensörler (Shivashankar ve Gopalakrishnan,2020) olarak kullanılabilir. Şu anda farklı birçok uygulama için değişik sensör türleri (kuvvet, sıcaklık, basınç vb.) kullanılmakta olup uygulanan yük veya elektrik akımına yanıt verebilmesi için bir güç kaynağına ihtiyaç duyar. Bununla birlikte, piezo elemanlar, bir güç kaynağına ihtiyaç duymadan uyarıcı etkiye cevap verebilecek özelliğe sahiptirler. Piezodirenç özellikli bu sensörler yapısal sağlık alanı (Kang vd., 2006; Lu vd., 2019), titreşim kontrol uygulamaları (Qureshi vd., 2015), robotik (Shihong vd., 2019; Kanoun vd., 2021) ve endüstriyel öneme sahip birçok alanda (Shimada vd., 2017) etkili bir şekilde kullanılabilir. Özellikle elastomer esaslı malzemeler ile üretilen araç lastiği, sönümleme takozu, hava süspansiyon yayları gibi nonlineer özelliklere sahip kompozit malzemelerin gerilim kaynaklı yapısal değişikliklerinin ve/veya mekanik hasarlarının anlık tespit edilebilmesi, ses veya optik görüntü işleme sensörleri (Wang vd., 1999; Kim vd., 2017) ile sağlanabilmektedir. Karbon allotropu olarak türetilen çok duvarlı karbon nanotüpler (MW-CNT) üstün elektriksel özelikleri nedeniyle akıllı malzemelerin üretiminde kullanılan geleneksel dolgulara alternatif olarak giderek daha fazla kullanılmaktadır. MW-CNT'ler ile üretilen Piezodirençli Elastomer Sensörler (PES) (Avilés vd., 2016), dinamik yük altında çalışan, çevre şartlarına karşı dayanıklı, ortam şartlarına uyum sağlayabilen farklı tiplerdeki pahalı sensörlerin ( Chen vd., 2016) yerine kullanılabilecek potansiyel bir aday olarak kabul edilebilir. MW-CNT'lerin piezo direnç özellikleri, iyi elektrik iletkenlikleri, ultra küçük çapları, yüksek en-boy oranları ve hafif olmaları nedeniyle yüksek performanslı ve çok işlevli PES'lerin üretiminde büyük potansiyele sahiptir. PES'in hassasiyeti kullanılan bu dolgu maddesinin matris içerisindeki konsantrasyonu, hizalanması, yönelimine bağlıdır (Alamusi vd., 2011; Oliva-Avilés vd., 2011). Son zamanlarda özellikle piezo özelliklere sahip kauçuk esaslı gerilim sensörlerinin hazırlanmasında karbon siyahları (Wichmann vd., 2009), grafen (Kim vd., 2011; Meeuw vd., 2016), karbon esaslı k1sa elyaflar (Yazıcı vd., 2017), karbon allotroplarından (Santos vd., 2019; Spinelli vd., 2018; Yin vd., 2011), oluşan çeşitli iletken dolgu maddeleri kullanılmıştır.

Mevcut çalışmamızda MW-CNT'ler ile hazırladığımız elastomer sensörlerin mekanik esnekliği ve dolgu malzemesinin sahip olduğu farklı uzunluklardaki şekilsel özellikleri önemli avantajlar sağlamaktadır. Eklenen dolgu malzemesi ile matris içerisinde oluşan yapısal değişiklikler sonucunda yüksek hassasiyetli iletken ağ oluşur. Dolgu oranına göre değişiklik gösteren bu iletim ağı, büyük ölçekli gerilmeler ve malzeme üzerinde oluşabilecek hasarların tespitinde gerekli mekanizmalarının etkinleşmesine neden olur. Yapılan çalışmanın amacı, numune üzerindeki mekanik gerilmeler ve bu gerilmelerin neden olduğu yapısal değişikliğe bağlı nanokompozit direnci arasındaki ilişkiyi incelemektir. Bunun için yedi farklı dolgu oranında elastomer nanokompozit hazırlanarak, farklı uzama değerlerinde iletken ağdaki deformasyona bağlı yapısal değişiklik kaynaklı direnç değişim ölçümleri yapılmıştır. Numunelere uygulanan gerilmeye bağlı olarak iletken ağdaki deformasyon ile oluşan direnç değişimini açıklamak için teorik bir model geliştirerek, testler ile yorumlanmıştır. Piezodirenç özellikli elastomer bir nanokompoziti hazırlamanın en basit yolu, uygun iletken dolgu malzemesini yeterli oranda yalıtkan bir matris içerisine doğru karıştırma yöntemleri ile katılarak sağlanmasıdır. Bu şekilde hazırlanan bir nanokompozitin içerisindeki dolgu maddesinin matris içerisinde düzgün bir şekilde dağılması ile istenen iletkenlik elde edilebilir. Numuneler üzerine herhangi bir şekilde mekanik bir yük uygulandığında, PES içerisindeki iletken ağ deforme olur, böylece malzeme direncinde önemli bir değişiklik vuku bulur. Piezodirenç özelliğe sahip elastomer nanokompozitlerin dışarıdan uygulanan yük karşısındaki direnç değişimi Keithley 2000 dijital multimetre ile ölçülerek, yük ve direnç değişimi arasındaki ilişki kurulmuştur. Doğal kauçuk esaslı MW-CNT dolgu malzemesi ile hazırlanmış nanokompozitlerin sergilediği piezo direnç özelliklerini incelenmiş, gerilim uygulamasının bu tür nanokompozitlerin elektrik direncini artırdığını gösterilmiştir (Bokobza, 2012). Doğal kauçuk esaslı karbon siyahı, MW-CNT ve karbon nanofiber dolgu malzemeleri ile hazırlanan nanokompozit numunelerine ait elastomer matris içerisindeki karbon nanotüp ve karbon nanofiber dolguları arasında oluşan karşılıklı etkileşimin, iletken ağın oluşumu ve kopması sonucunda ortaya çıktığını, buna bağlı olarak da kararlı ya da kararsız piezo dirençlilik davranış sergilemiştir (Qingliang He vd., 2014). Robotik parmak algılama uygulamaları için grafen nano tabakalardan oluşan silikon kauçuk esaslı kompozit malzemeden hazırlanan numuneler üzerindeki gerilmenin arttırılmasıyla, kompozitin elektriksel direncinin $\operatorname{arttığ~}$ görülmüştür. $\mathrm{Bu}$ fenomeni açıklamak için, uygulanan yüklemeye bağlı olarak matris içerisindeki dolgu partiküllerinin deformasyonunu ve bu deformasyona bağlı iletken yolların tahribatını da incelenmiş ve hacimce \%1.36 oranında kullanılan grafen nano dolgulu nanokompozitin çok düşük basınç altında bile oldukça duyarlı piezo direnç özellik sergilemiştir (Chen vd., 2007). Karboksil ile modifiye edilmiş karbon nanotüp dolgular ile hazırlanan silikon kauçuk numeneleri içersindeki karbon nanotüplerdeki karboksil grubunun, kauçuk matris içerisinde karbon nanotüplerin dağılımı ve hizalamasını iyileştirerek kompozit numunesinin elektriksel açidan hassasiyetinin iyileşmektedir (Wang vd., 2010). Epoksi/cam elyaf takviyeli kompozitlerde darbe hasarını yerinde tespit etmek için MWCNT iletken dolgu maddesi kullanarak, gerilme dağılımını değerlendirilmiş ve gerilmenin artmasıyla dirençteki farklı değişim aşamaları; hasar başlangıcı, hasarın ilerlemesi ve hasarın sonlandırılması algılanmıştır (Gao vd., 2011). İletken dolgulu polimer kompozitlerine uygulanan tek eksenli basınç değerindeki artış kompozitin toplam direncini azaltmıştır. Bu durum kompozitlerin mikro yapısı içerisindeki "iletken yol" kavramı ile tanımlanır. Her bir iletken yol iletken parçacıklardan oluşur ve nanokompozit içersindeki toplam direnç, iletken parçacıklar arasındaki direnç tarafından belirlenir (Zhang vd. 2000). Farklı miktarlarda karbon siyahı dolgulu silikon kauçuk kompozit numunelerinin piezo direnç özeliklerini tanımlamak için önerilen çeşitli matematiksel modeller mevcuttur (Wang vd., 2009). Karbon siyahı dolgulu poliizopren kompozitin gerilme ve elektrik direnci arasındaki ilişkiye bağlı olarak, iletken dolgulu nanokompozit $20{ }^{\circ} \mathrm{C}$ ila $60{ }^{\circ} \mathrm{C}$ aralığında bir sensör olarak etkili bir şekilde kullanılabilir(Knite vd., 2004). Doğal kauçuk esaslı MW-CNT dolgu malzemesi ile farklı konsantrasyonlarda hazırlanan numunelerin elektriksel direnç değişiminin gerilme ile doğrusal olmayan bağımlılığ 1 için geliştirilen teoriye göre, oldukça yüksek uzama değerleri için 
iletken elastomer kompozitler piezo direnç özellikleri sergileyen bir gerilim sensörü olarak kullanılabilir (Chervanyov vd., 2016).

Yapılan literatür araştırmaları dış uyaranların etkisinin çok düşük olduğu durumlarda bile hazırlanan kompozitlerin, piezo direnç mekanizmalarının deneysel olarak iyi çalıştığını göstermektedir. Kompozitin direncindeki büyük değişiklikler kompozit matrisi içerisindeki iletken dolgu parçacıkları arasındaki mesafenin gerilmeye bağlı olarak değişmesi ile açıklanabilir. Çalışmada elde edilen deneysel sonuçlar incelendiğinde, çekme gerilmesi ile değisşen elektrik direnci arasında non-lineer bir ilişki mevcuttur. Uygulanan yüzdesel uzama miktarlarındaki değişkenliğe bağlı olarak kompozitin içyapısında iletken dolguların oluşturduğu iletkenlik ağ mekanizmasında değişkenlikler gözlenmiştir. Nanokompozit numunelerindeki bu davranışı açıklayabilmek için malzemenin elektriksel direnci ile matris içyapısı arasındaki ilişkiye ait bir model oluşturulmuştur. Çalışmamız sonucunda elde edilen kauçuk esaslı MW-CNT iletken dolgulu nanokompozit karışımları ile üretilen piezodirenç özelliklerine sahip elastomerlerin çok geniş bir uygulama alanında gerilim sensörü olarak kullanılabileceğini göstermiştir.

\section{Materyal ve Metot}

\subsection{Malzemeler}

Çalışmamızda kullanılan kauçuk grupları SMR20, CBR 1203, Kraiburg $\mathrm{GmbH}$, Almanya'dan temin edilmiştir. Ortalama partikül büyüklüğü 40-48 nm, yüzey alanı $36-52 \mathrm{~m}^{2} / \mathrm{g}$ olan ve ana dolgu maddesi olarak kullanılan karbon siyahı (FEF N550) Anlaş Lastik A.Ş., Türkiye'den temin edilmiştir. Ağırlıkça \%3.7 karboksilik asit (-COOH) içeriğine sahip, spesifik yüzey alanı $510 \mathrm{~m}^{2} / \mathrm{g}$ ve $2.4 \mathrm{~g} / \mathrm{cm}^{3}$ gerçek yoğunluğa sahip ve elektrik iletkenliği $98 \mathrm{~S} / \mathrm{cm}$ olan fonksiyonlaştırılmış çok duvarlı karbon nanotüpler (dış çap $<8 \mathrm{~nm}$, iç çap 2-6 nm, uzunluk $\sim 10-35 \mu \mathrm{m}$ ve $>\% 96$ saflık) Nanografi Co. Ltd., Türkiye'den satın alınmıştır. Stearik asit, proses yağı, TMQ(1,2dihidro-2,2,4-trimetil-kinolin), IPPD (N-izopropil-N'-fenil-pfenilendiamin) çinko oksit ( $\mathrm{ZnO}$ ), sülfür (S80), CBS (NSikloheksil-2-benzotiyazol sülfenamid), antiozonant vaks gibi diğer tüm karışım bileşenleri ticari ürünler olarak temin edilmiştir. Karışım içerisinde kullanılan proses yağı parafinik tipte olup $0.849 \mathrm{~g} / \mathrm{cm}^{3}$ yoğunluğa sahiptir. Reçete içeriğindeki tüm bileşenler phr (per hundred rubber) biriminde formülasyona eklenmiştir. Hazırlanan karışımların reçetesi Tablo 1'de gösterilmiştir.

\subsection{Nanokompozit Numunelerinin Hazırlanması}

Kauçuk esaslı iletken nanokompozit numuneleri gerçek üretim koşullarına uygun olacak şekilde iki aşamada hazırlanmıştır. İlk aşamada kauçuk grubuna herhangi bir bileşen eklenmeden 7 dakika boyunca karıştırılarak yumuşatılmıştır. Ardından karbon siyahı dolgu maddesi (FEF N550 sinıfi, 45 phr) ve diğer kimyasallar (hızlandırıcılar, plastikleştiriciler, parafinik yağ, ozon vaks vb.) belirli bir sırayla kauçuğa ilave edilerek (Peng vd., 2010), $100{ }^{\circ} \mathrm{C}^{\prime} \mathrm{de} 20$ dakika boyunca karıştırılmıştır. Birinci aşama sonunda elde edilen ana karışım oda sıcaklığında on altı saat dinlendirilip ikinci aşamaya geçilmiştir. İkinci aşama, ana karışımın MW-CNT iletken dolguları ve çapraz bağlayıcılarla iki milli açık bir karıştıııııda
20 dakika süreyle $75{ }^{\circ} \mathrm{C}^{\prime} \mathrm{de}$ ve $40 \mathrm{rpm}$ silindir hızında gerçekleştirilmiştir. İletken dolguların homojen bir şekilde dağılması için karışımdaki dolgu izleri kaybolana kadar sürekli çevrim sağlanmıştır. Karıştırma işlemi sonlanmadan 3 dakika önce pişirici grubu ilave edilmiş ve oda sıcaklığında karışımın olgunlaşması için dinlenmeye bırakılmıştır. Hazırlanan karışım numunelerinin viskoelastik özellikleri MDR 3000 Rheometer (Montech, Almanya) test cihazında $165{ }^{\circ} \mathrm{C}^{\prime} \mathrm{de} \quad 8$ dakika vulkanize edilerek belirlendi. Maksimum tork $\left(\mathrm{M}_{\mathrm{H}}\right)$, minimum tork $\left(\mathrm{M}_{\mathrm{L}}\right)$, skorch zamanı $\left(\mathrm{ts}_{2}\right)$ ve nihai torkun \%90'ına ulaşmak için gereken süre $\left(t_{90}\right)$ gibi vulkanizasyon parametreleri tespit edilmiştir.

\subsection{Nanokompozit Morfolojisi}

MW-CNT ile hazırlanan nanokompozit karışımları bir Taramalı Elektron Mikroskobu (SEM) $(20 \mathrm{kV}$ voltaj hassasiyeti, Vega 3 Tescan) ile incelenmiştir. Nanokompozit numuneler, analizden önce $4 \mathrm{~nm}$ kalınlığında altın (Au) ile kaplanmıştır. Şekil 1a ve b'de verilen SEM görüntüleri incelendiğinde MWCNT'nin geniş en-boy oranını ve dolanma dereceleri net bir şekilde görülmektedir. MW-CNT'ler, kauçuk matris içerisinde az sayıda topaklanma ile homojen bir dağılım sunar ve bireysel nano iletkenler seviyesinde birbirine bağlı bir dolgu ağı oluşturur. MW-CNT'ler polimer matris içinde homojen olarak dağılmıştır. Bu durum, MW-CNT'lerin potansiyel olarak düşük temas direncine sahip yüksek oranda birbirine bağlı bir ăg oluşturabileceğini, elektriksel iletkenliği ve gerilim transferini etkili bir şekilde iyileştirebileceğini göstermektedir.
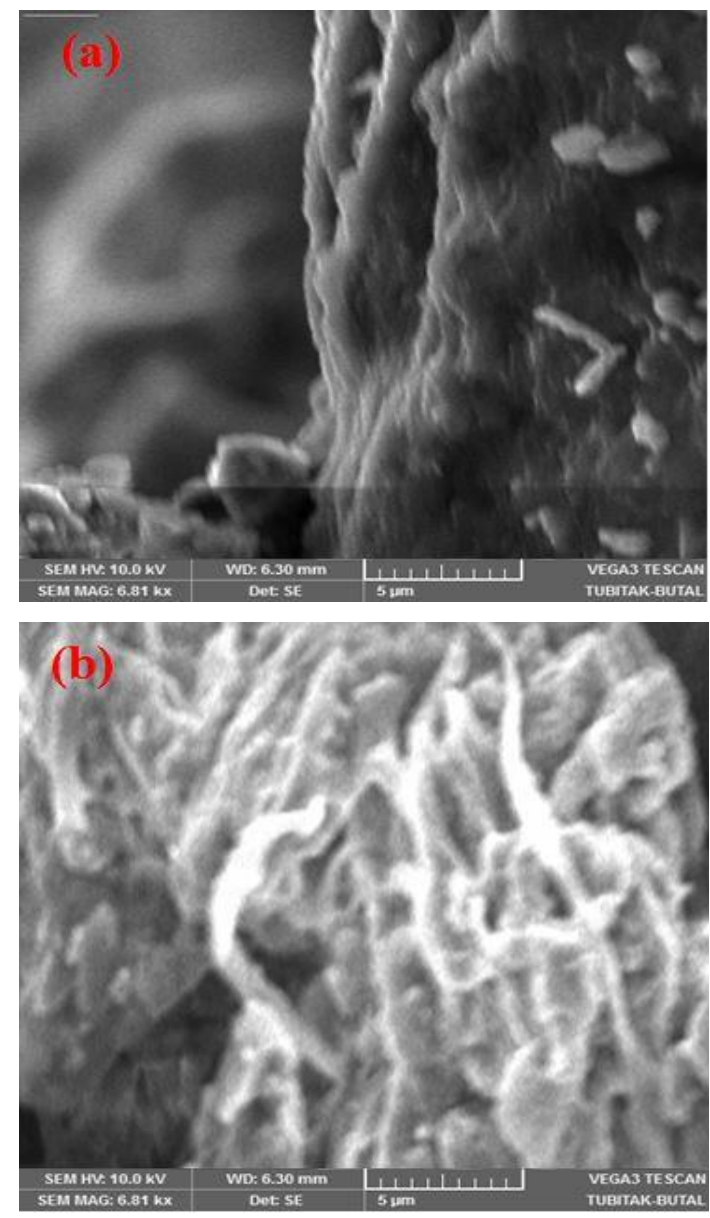

Şekil 1. Nanokompozit Numuneleri SEM Görüntüleri 
European Journal of Science and Technology

Tablo 1. Kauçuk Esaslı Nanokompozit Karılım Formülasyonuı

\begin{tabular}{|c|c|c|c|c|c|c|c|c|c|c|c|c|}
\hline & \multicolumn{2}{|c|}{$\begin{array}{c}\text { Kauçuk } \\
\text { Grubu }\end{array}$} & \multicolumn{2}{|c|}{ Dolgu Grubu } & \multicolumn{5}{|c|}{ Kimyasal Grubu } & Yağlar & \multicolumn{2}{|c|}{$\begin{array}{l}\text { Pişirici } \\
\text { Grubu }\end{array}$} \\
\hline & $\begin{array}{c}S M R \\
20\end{array}$ & $\begin{array}{l}\text { CBR } \\
1203\end{array}$ & $\begin{array}{l}\text { FEF } \\
N 550\end{array}$ & $\begin{array}{l}M W- \\
C N T\end{array}$ & $\mathrm{ZnO}$ & $\begin{array}{c}\text { Stearik } \\
\text { Asit }\end{array}$ & $I P P D$ & $\begin{array}{l}\text { Ozon } \\
\text { Vaks }\end{array}$ & $T M Q$ & $\begin{array}{c}\text { Parafinik } \\
\text { Yağ }\end{array}$ & $S 80$ & $C B S$ \\
\hline $\begin{array}{l}\text { Numune } \\
\text { Karlşım } \\
\text { Oranlart (nhr) }\end{array}$ & 50 & 50 & 45 & $(*)$ & 2.2 & 2 & 1.1 & 1.1 & 1.3 & 10 & 2.3 & 1.5 \\
\hline
\end{tabular}

(*) MW-CNT dolgu oranları sırasıyla 0,5 , 2, 3,5 , 5 , 8 , 10 phr olarak kullanılmıştır.

\subsection{Nanokompozitlerin Elektriksel Karakterizasyonu}

Elastomer esaslı nanokompozit numunelerinin doğru akım elektrik iletkenlikleri $10^{7} \mathrm{~S} / \mathrm{m}^{\prime}$ nin üzerinde olduğu durumlarda dijital bir multimetre (Keithley Instruments Model 2000) kullanılarak ölçülmüştür. Numune boyutları, test makinesine (Zwick/Roell Z010) kolay bağlantı sağlamak ve ölçüm problarını kolayca takmak için $40 \mathrm{~mm}$ uzunluğunda, $15 \mathrm{~mm}$ genişliğinde ve $2 \mathrm{~mm}$ kalınlığında özel bir kesme kalıbı kullanılarak elde edilmiştir. $10^{7} \mathrm{~S} / \mathrm{m}^{\prime}$ nin altındaki iletkenlik değerine sahip yüksek dirençli nanokompozitler için Keithley Instruments Model $6517 \mathrm{~b}$ tipi dijital bir elektrometre kullanılmıştır. Direnç ölçümlerinde yüzey etkilerini en aza indirmek için numunelerin uçları yalıtkan bantlar ile tamamen sarılarak ölçüm cihazının sabitleme çenelerine bağlanmıştır. Elektrotlar arasına 10 V'luk bir DC voltaj uygulanmıştır ve numunelerin elektrik direnci $\left(R_{m}\right)$ Denklem (1) ile ölçülmüştür.

$$
R_{m}=\rho \frac{t}{A_{c}}
$$

Burada $\operatorname{Rm}(\Omega)$ kompozit numunelerinin ölçülen elektriksel direnci, t (m) numune kalınlığ $1, A_{c}$ numunenin kesit alanı $\left(\mathrm{m}^{2}\right), \rho$ $(\Omega \mathrm{m})$ kompozit malzemelerin elektrik akımının akışına direnme gücünü belirten özdirencini ifade eder.

$$
\sigma_{i}=\frac{1}{\rho}
$$

$\sigma_{\mathrm{i}}(\mathrm{S} / \mathrm{m})$ numunelerin iletkenliği olup Denklem (2) ile ifade edilir.

\subsection{Nanokompozitlerin Piezodirenç Karakterizasyonu}

Piezodirenç ölçümleri, Şekil 2' de gösterildiği gibi, çekme test makinasında (Zwick/Roell Z010, Almanya) gerçekleştirilmiştir. Numune geometrisi ve boyutları, ASTM standardı D 412'ye uygun olacak şekilde seçildi. Numunelerin bağlama çenelerine denk gelen kısımları yalıtkan maskeleme bandı ile sarılmıştır. Testler sırasında çekme test makinasının hareketli kafası $1 \mathrm{~mm} / \mathrm{dk}$ hızında hareket ettirilmiş ve numuneler üzerindeki uzama değerleri otomatik olarak hareketli kısım üzerinden alınmıştır. Uzama sırasındaki elektrik direnci Keithley Instruments Model $6517 \mathrm{~b}$ tipi dijital bir elektrometre kullanılarak ölçülmüş, test boyunca Labview yazılımı ile kayıt alınmıştır. Ölçüm probları numune üzerine tam temas edecek şekilde tutturulmuş ve iki prob arasındaki mesafe $15 \mathrm{~mm}$ olacak şekilde ortalanmıştır. Mekanik olarak testlere başlamadan önce tüm numunelerin elektriksel direnç değerleri bir dakika boyunca kayıt altına alınmıştır. Her malzemeden beş numune test edilmiştir. Ölçümler, $23 \pm 0.5^{\circ} \mathrm{C}$ sıcaklığında ve \% $50 \pm 2$ nem değerinde gerçekleştirilmiştir. Nanokompozitlerin hassasiyetleri piezodirenç (Pr) özelliklerine bağlıdır ve Denklem (3) ile ifade edilir.

$$
\mathrm{P}_{\mathrm{r}}=\frac{\Delta \mathrm{R}}{\mathrm{R}_{0}}
$$

Burada $\Delta \mathrm{R}$ ve $\mathrm{R}_{0}$, sırasıyla numuneye yük uygulandığında meydana gelen uzamaya bağlı direnç değişimi ve başlangıç direncidir.

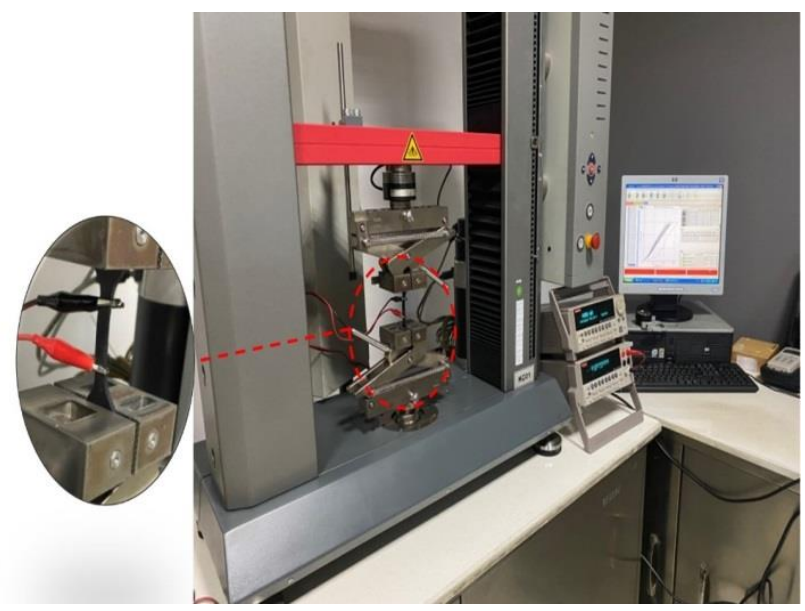

Şekil 2.Piezodirenç Ölçümleri İçin Deney Düzeneği

\section{Araştırma Sonuçları ve Tartışma}

\subsection{Elastomer Esaslı Nanokompozitlerinin (ECN) Elektriksel İletkenliği}

İletken dolgu maddelerinin polimer malzemelere dâhil edilmesiyle elde edilen nanokompozitler elektronik uygulamalar için büyük potansiyele sahiptirler. $\mathrm{Bu}$ uygulamalar için genellikle nanokompozitlerin farklı elektriksel özellikleri kullanılır. Elektromanyetik uygulamalar için hazırlanan nanokompozitlerin alternatif akım (AC) özellikleri gerekliyken, gerinim sensörlerinin uygulanması için nanokompozitlerin doğru akım (DC) özelliklerine ihtiyaç vardır. Kompozitin elektriksel özellikleri, matris olarak kullanılan elastomerde bulunan iletken dolgu fazının miktarı ve yapısı tarafından belirlenir. Bir yalıtım malzemesi olarak saf kauçuk için doğru akım altında yapılan ölçümlerde $10^{-14} \mathrm{~S} / \mathrm{m}$ düzeyinde bir elektrik iletkenliği elde edilmiştir. $\mathrm{Bu}$ durum yalıtım malzemesinden beklenen bir durumdur. MW-CNT dolgu miktarının arttırılmasıyla, nanokompozitin elektriksel iletkenliğinin yalıtkan alandan yarı iletken alana ve ardından iletken alana kademeli bir şekilde geçmesi beklenir. Şekil 3'de MW-CNT dolgu malzemesinin ECN'lerin elektriksel iletkenliği üzerindeki etkisi gösterilmiştir.

MW-CNT'nin kademeli olarak eklenmesi ile elektriksel iletkenliği önce yavaş bir şekilde ardından keskin bir şekilde 
artış göstermiştir. Şekil 3'de gösterilen iletken dolgu miktarına bağlı elektriksel iletkenlik değişimi üç farklı aşamaya bölünebilir.

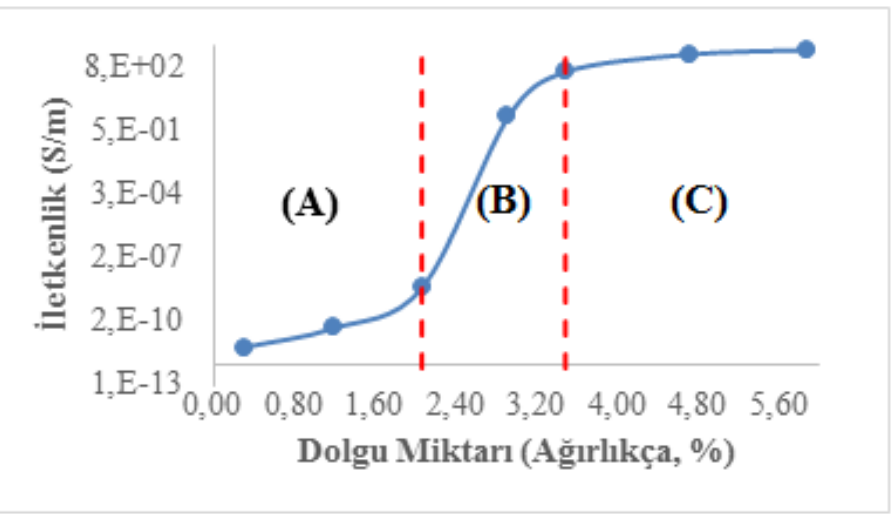

Şekil 3. Piezodirenç Ölçümlerinde MW-CNT dolgu malzemesinin ECN'lerin elektriksel iletkenliği üzerindeki etkisi

Ağırlıça \%0.3 ile 2.06 arası birinci bölge olarak tanımlanan iletkenlik etkileşim başlangıcı (A), \%2.06 ile 3.48 arasında süzülme eşiği olarak isimlendirilen ikinci bölge(B), \%3.48 ile 5,88 arasındaki iletken ağı tam olarak oluştuğu üçüncü bölge $(C)$ olarak tanımlayabiliriz. Bu bölgelerdeki iletken dolguların matris içerisindeki dağılımları Şekil 4'de şematik olarak gösterilmiştir. Ağırlıkça \% 0.3-1.19 arasında elektriksel iletkenlik çok düşük olup lineer bir şekilde artmaktadır. Bu bölgede ECN'lerin elektriksel iletkenliği polimer matrisinkine yakındır. Birbirine yakın iletken dolgu sayısı artmaktadır. Ağırlıç̧a \%2.06 ulaşıldığında MW-CNT'ler arasında tam bir iletken yol olmamasına rağmen, iletken dolgular arasındaki tünelleme etkisi (Simmons, 1963; Rahman vd., 2012) nedeniyle elektriksel iletkenlik kademeli olarak artmaya başlamıştır. Buradaki durum nanokompozitin piezodirenç karakterizasyonu için önemlidir. Ağırlıkça \%2.06 ile 2.92 arasında MW-CNT'lerin miktarı artması ile nanokompozitin elektriksel iletkenliği dikkat çekici bir şekilde artmıştır. Bu dolgu aralığında ECN'lerin iletkenliği 6.97E-09 S/m'den 2.56 S/m'ye aniden değişmiştir. İletkenlikteki bu gözlenen sıçrama kritik dolgu malzemesinin miktarı ile ortaya çıkan süzülme eşiği ile ilişkilidir (Bauhofer vd., 2009; Perets vd., 2020; Chen vd., 2018) . Belirlenen kritik dolgu malzemesi miktarı, MW-CNT'lerin boyutsal özelliklerine, enboy oranlarına, matris içerisinde dağılımına ve hizalanma yapısına bağlıdır (Chanklin vd., 2018; Ning $\mathrm{Hu}$ vd., 2008; Sánchez-Romate vd., 2016). MW-CNT'lerin bu kritik miktarın üzerinde eklenmesi, kalıcı bir iletken ağın kurulmasına ve eğrinin yatay konuma gelmesi ile sonuçlanır. Ağırlıkça \%3.48'den 5.88'e arttırılmasıyla, ECN'lerin iletkenlikleri $4.44 \mathrm{E}+02$ ile $5.56 \mathrm{E}+03$ aralığında kalır. MW-CNT'lerin matris içerisinde rastgele hizalanması ve homojen dağılımı yüksek iletkenlik ağına sahip ve sürekli birbirine bağlana bir dolgu ağının oluşumunu kolaylaştırır (Yang vd., 2021; Yazdani-Pedram vd., 2017). ECN'ler içerisinde süzülme eşiğine bağlı olarak iletken bir ağ oluşturmak için yeterince dolaşmış ve birbirine bağlanmış MW-CNT'ler bulunmaktadır (Şekil 1).

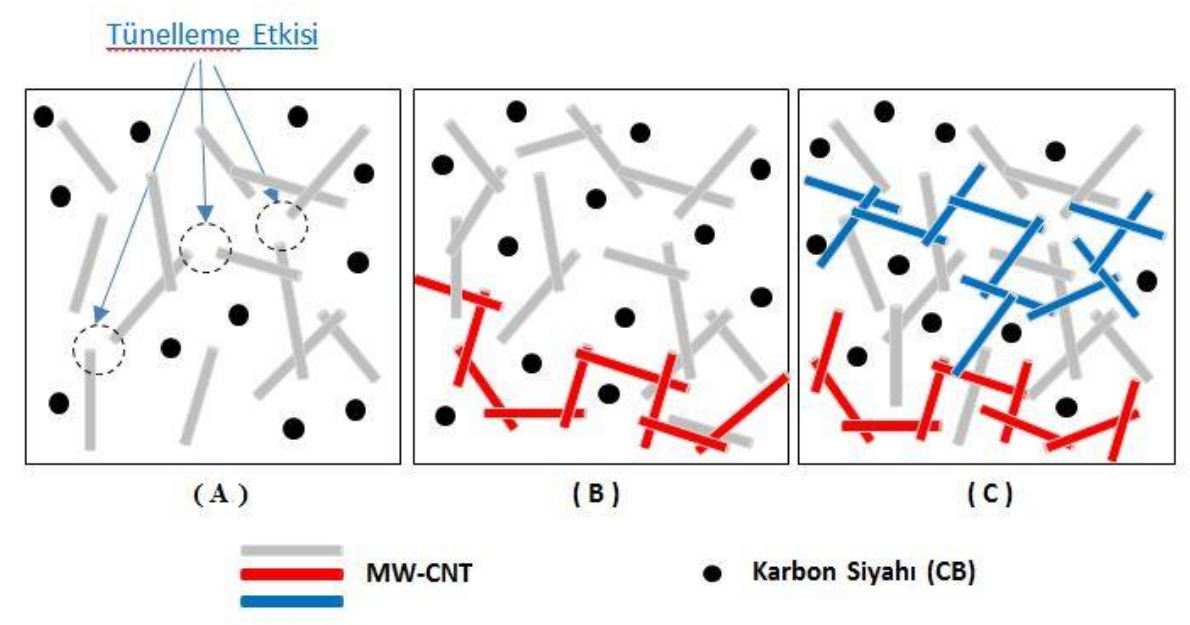

Şekil 4. ECN’lerdeki dolgu malzemelerinin süzülme eşiği davranışı

\subsection{ECN Nanokompozitlerin Piezodirenç Davranışları}

Elastomer esaslı nanokompozitlerin piezodirenç tepkilerini araştırmak için bir dizi çekme-uzama deneyi gerçekleştirilmiştir. Şekil 5'de çeşitli MW-CNT dolgu miktarları ile hazırlanan karışımlar için uygulanan yüzdesel uzamanın bir fonksiyonu olarak elde edilen piezodirenç değişimi gösterilmektedir. Uygulanan gerilim arttıkça tüm numunelerin direnci artar. Piezodirenç değişiminde meydana gelen bu durum; (i) uygulanan uzamaya bağlı olarak iletken ağın yeniden inşası ( iletken yolların oluşturulması ya da yok olması), (ii) MWCNT'ler arasındaki mesafe değişiklikleri ve (iii) karbon nanotüpler arasındaki temas noktalarının yoğunluk şeklinde üç ana mekanizma ile açıklanabilir. MW-CNT dolgu miktarına bağlı olarak numuneler farklı yanıt vermektedir. Yapılan piezodirenç ölçümlerinde elde edilen grafik incelendiğinde iki farklı davranış şekli gözlemlenmektedir.

Süzülme eşiğinin oluştuğu dolgu miktarlarının çok üzerinde MW-CNT içeren nanokompozitlerin (\% 3.48 , \% 4.71 , \% 5.88) piezodirenç yanıtı doğrusal ya da yarı doğrusaldır. Bunun yanında süzülme eşiği etrafında dolgu içeriğine sahip nanokompozitler (\%2.06 , \% 2.92) için uzamanın bir fonksiyonu olarak piezodirenç tepkisi doğrusal olmayan bir davranış ortaya koyar. $\mathrm{Bu}$ numunelerin piezodirenç davranışı kritik bir uzama seviyesine kadar doğrusal olup sonrasında üstel olarak değişir. A ğırlıkça \%2.06, \%2.92 ve \%3.48 oranlarında MW-CNT içeren nanokompozitler için kritik yüzde uzama değeri \%90 civarında tanımlanmıştır. Kritik yüzdesel uzama değerinin altındaki kısım 1.bölge olarak tanımlanırken, kritik yüzdesel uzamanın üzerindeki alan 2.bölge olarak tanımlanmıştır. 


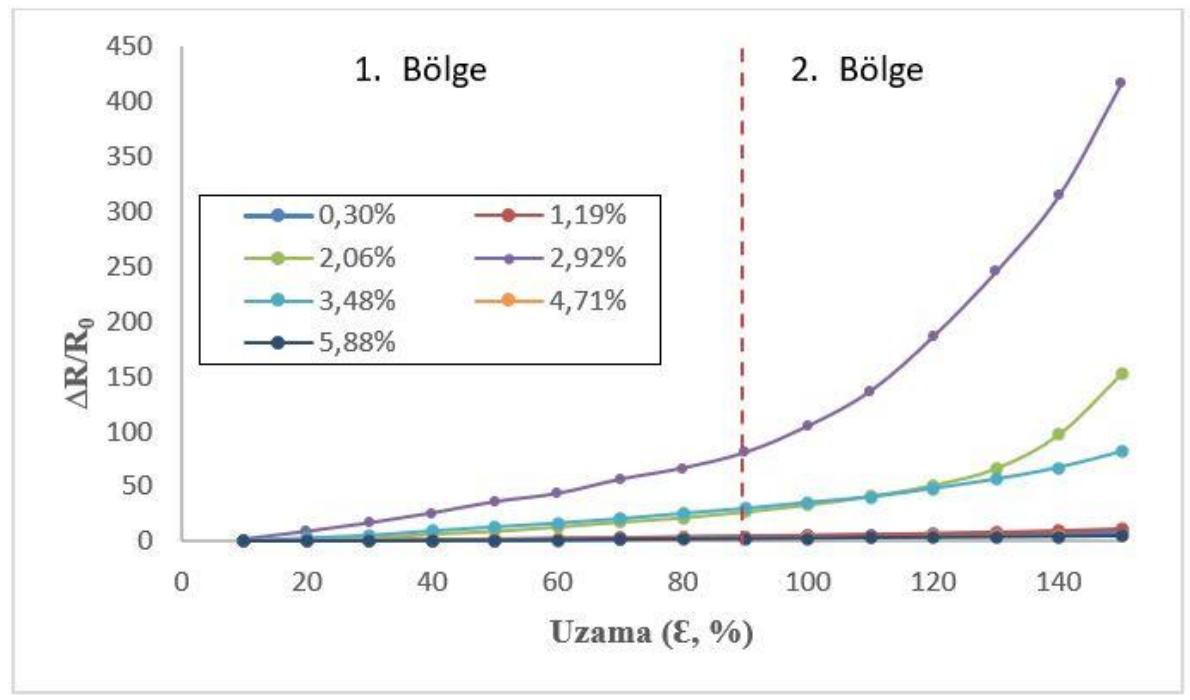

Şekil 5.MW-CNT dolgu miktarları için uzamanın bir fonksiyonu olarak piezodirenç değişimi

Ağırlıkça $\% 0.3$ ve $\% 1.19$ oranında MW-CNT içeren nanokompozitler yalıtkan özelliklere sahiptirler. Bu malzemeler piezodavranış sergilemezler. Ağırlıkça \%2.92 oranında MWCNT içeren nanokompozit artan yüzdesel uzamaya bağlı olarak direnç değerinde en büyük değişikliği gösterir. \%2.92 oranında iletken dolgu içeren nanokompozitin duyarlılığı ağırlıkça \%3.48 oranında MW-CNT içeren nanokompozite kıyasla daha yüksektir. Bunun nedeni kümelenmiş ve dolaşık yapılar oluşturan karbon nanotüplerin daha yüksek oranda olmasından kaynaklanmaktadır. Dolgu miktarı arttıkça, matris içerisindeki MW-CNT arasındaki mesafe azalır ve topaklaşma yoğunluğu artar. Bu nedenle, daha yüksek dolgu miktarında, MW-CNT arasındaki mesafeyi artırmak ve iletken ağı yok etmek için daha yüksek yüzdesel uzama değerlerine ihtiyaç duyulur. Nanokompozitlerin süzülme eşiğinin üzerinde dolgu maddesi miktarı ile kullanılmasının avantajı, daha yüksek büyüklükteki uzamaları algılama yeteneğidir İletken şebekeyi yok etmek için nispeten daha yüksek yüzdesel uzama değerlerine ihtiyaç olduğunu gösteren test sonuçları şekil 6'da gösterilmiştir. Yaklaşık \%300 uzama değerini, ağırlıkça $\% 4.71$ ve $\% 5.88$ dolgu oranına sahip ECN'ler algılayabilmektedir.

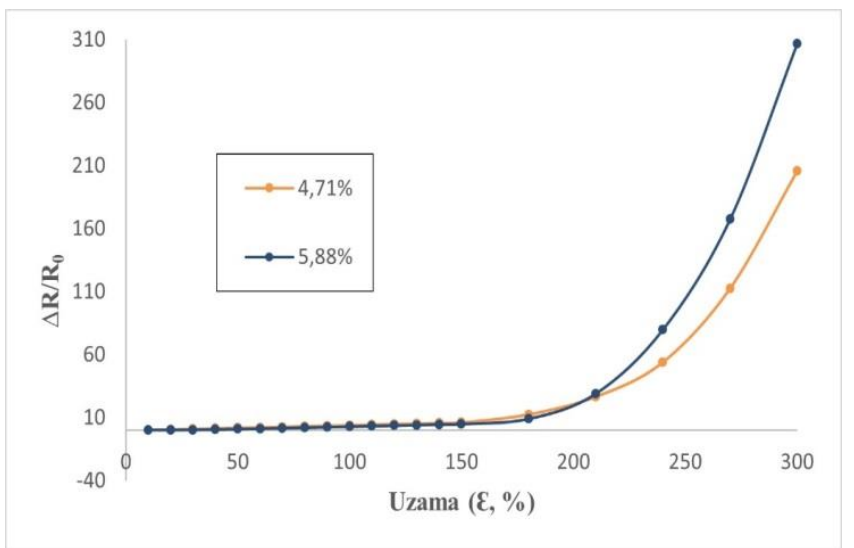

Şekil 6. Yüksek dolgu miktarları için uzamanın bir fonksiyonu olarak piezodirenç değişimi

\%2.92 oranında MW-CNT dolgulu karışım nispeten daha az yoğun ve dolaşık iletken ağlara sahip olduğu için düşük uzamalarda bu ağların kııılması gerçekleşmektedir. Tarif edilen iletkenlik mekanizması şekil 4 de gösterilmiştir. Yukarıda tartışıldığı gibi, süzülme eşiğine yakın MW-CNT dolgulu nanokompozitlerin iletkenliğine tünelleme mekanizması hâkimdir (Balberg, 1987). Piezodirençli bir malzemenin hassasiyeti, ölçüm faktörü (GF) olarak isimlendirilen ve Denklem (4) de gösterildiği şekliyle tanımlanır:

$G F=\frac{\frac{\Delta R}{R_{0}}}{\Delta \varepsilon}$

Burada, $\mathrm{R}_{0}$, nanokompozitin hareketsiz haldeki başlangıç direnci, $\Delta \mathrm{R}$, direnç değişimi ve $\Delta \varepsilon$ yüzdesel uzama miktarındaki değişimdir.

Şekil 7, ECN'lere yapılan piezodirenç değişim testlerinden elde edilen eğrilerin eğimi olarak tanımlanan ölçüm faktörünü (GF) gösterir. Nanokompozit için en yüksek piezodirenç duyarlılığı, süzülme eşiğinin hemen üzerinde bir MW-CNT dolgu miktarları içeren numuneler için elde edilmiştir. Ağırlıkça \%2.92 MW-CNT içeren ECN'nin \%100'lik bir uzama seviyesi için yaklaşık 105 birimlik bir ölçüm faktörü göstermiştir. MWCNT miktarı süzülme eşiğinden uzaklaştıkça, ölçüm faktörünün de büyük ölçüde azaldığı görülmektedir. Bu nedenle yüksek dolgu miktarına sahip nanokompozit numunelerin daha az hassas olmasına bağlı olarak ağırlıkça \%2.92 oranında (elektriksel süzülme eşiğinin biraz üstünde) numuneler seçilerek, zamana bağlı tekrarlı sensör testleri gerçekleştirilmiştir.

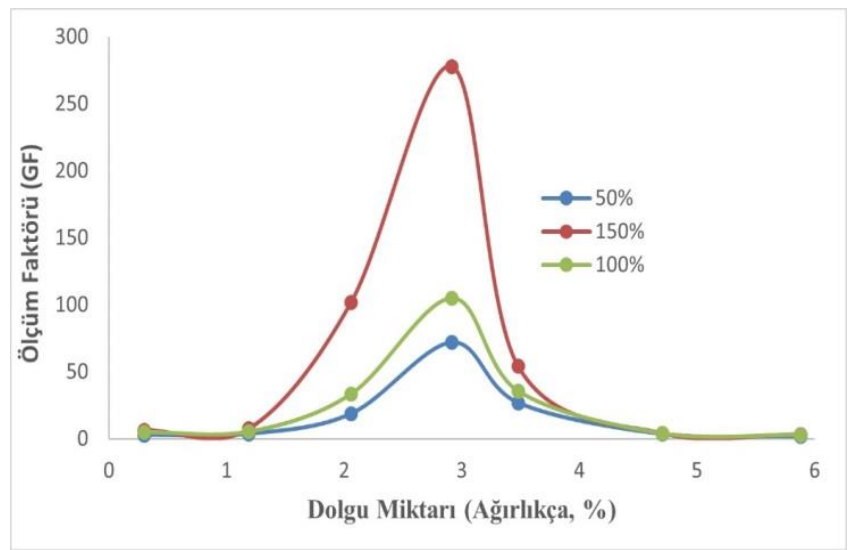

Şekil 7. \%50, \%100 ve \%150 uzamalardaki ölçüm faktörleri (GF) 
Ölçüm faktörü grafiği dikkatlice incelendiğinde ağırlıkça MW-CNT miktarlarındaki küçük bir değişikliğin, uygulanan uzama miktarına bağlı olarak matris içerisindeki dağılım kalitesinden dolayı piezodirenç davranışlarında ciddi değişikliklere neden olabileceği düşünülmüştür.

MW-CNT ağının piezodirenç davranışı, matris içerisindeki boyutsal değişikliklere bağlı direnç $\mathrm{R}_{\mathrm{M} / \mathrm{b}}$, karbon nanotüpler arasındaki mesafeden kaynaklı tünelleme direnci $\mathrm{R}_{\mathrm{MW}-\mathrm{CNT} / \mathrm{t} \text {, }}$ karbon nanotüpler arasındaki temas ve içsel dirençlerine bağlı olarak karmaşık bir etkileşim şeklinde tarifleyebiliriz (Meguid vd., 2019). Nanokompozit içerisinde direnç değişikliğinde etkin olan bu parametreleri göz önünde bulundurduğumuz zaman Denklem (3) ile verilen piezodirenç değişimini Denklem (5)'deki gibi toplam direnç değişimi olarak tanımlayabiliriz.

$\frac{R-R_{0}}{R_{0}} \approx \frac{R_{M b}-R_{M b 0}}{R_{M b 0}}+k \cdot \frac{R_{M W-C N T / t}-R_{M W-C N T / t 0}}{R_{M W-C N T / t 0}}$

Denklem (5)'de verilen k, katsayısını nanaotüpler arasındaki tünelleme direncinin, matris içerisindeki boyutsal değişikliklere bağlı direnç değişimine oranı olarak Denklem (6)'daki şekildedir.
$k=\frac{R_{M W-C N T / t 0}}{R_{M b}}$

Nanotüpler arasındaki tünelleme direnci, nanotüpler arasındaki ayrımın bir fonksiyonu olarak üstel olarak değişir. Bu nedenle, temas geometrisindeki küçük değişiklikler, büyük direnç değişikliklerine neden olabilir (Das vd., 2017; Xu vd.,2013).

\subsection{Tekrarlı Yüklemeler Altında ECN'lerin Piezodirenç Davranışları}

Ağırlıkça \%2.92 oranında MW-CNT dolgulu nanokompozitlerin piezodirenç değişim testleri, zamanın bir fonksiyonu olarak $\% 90$ ve $\% 150$ uzama seviyelerinde sekiz çevrim şeklinde ölçülmüştür. Nanokompozite ait piezodirenç tekrarlanabilirliğine ait çevrimli yükleme grafikleri Şekil 8'de gösterilmiştir. Kritik uzama seviyesi \%90'a kadar elde edilen çevrimli yükleme grafikleri şekil 8a'da, \%150'ye kadar elde edilen çevrimli yükleme grafikleri şekil 8 b'de gösterilmiştir. Çekme gerilmesi uygulandığında direnç artar ve gerilme gevşemesi altında azalır (Kasim vd., 2021; Kalantari vd., 2012).
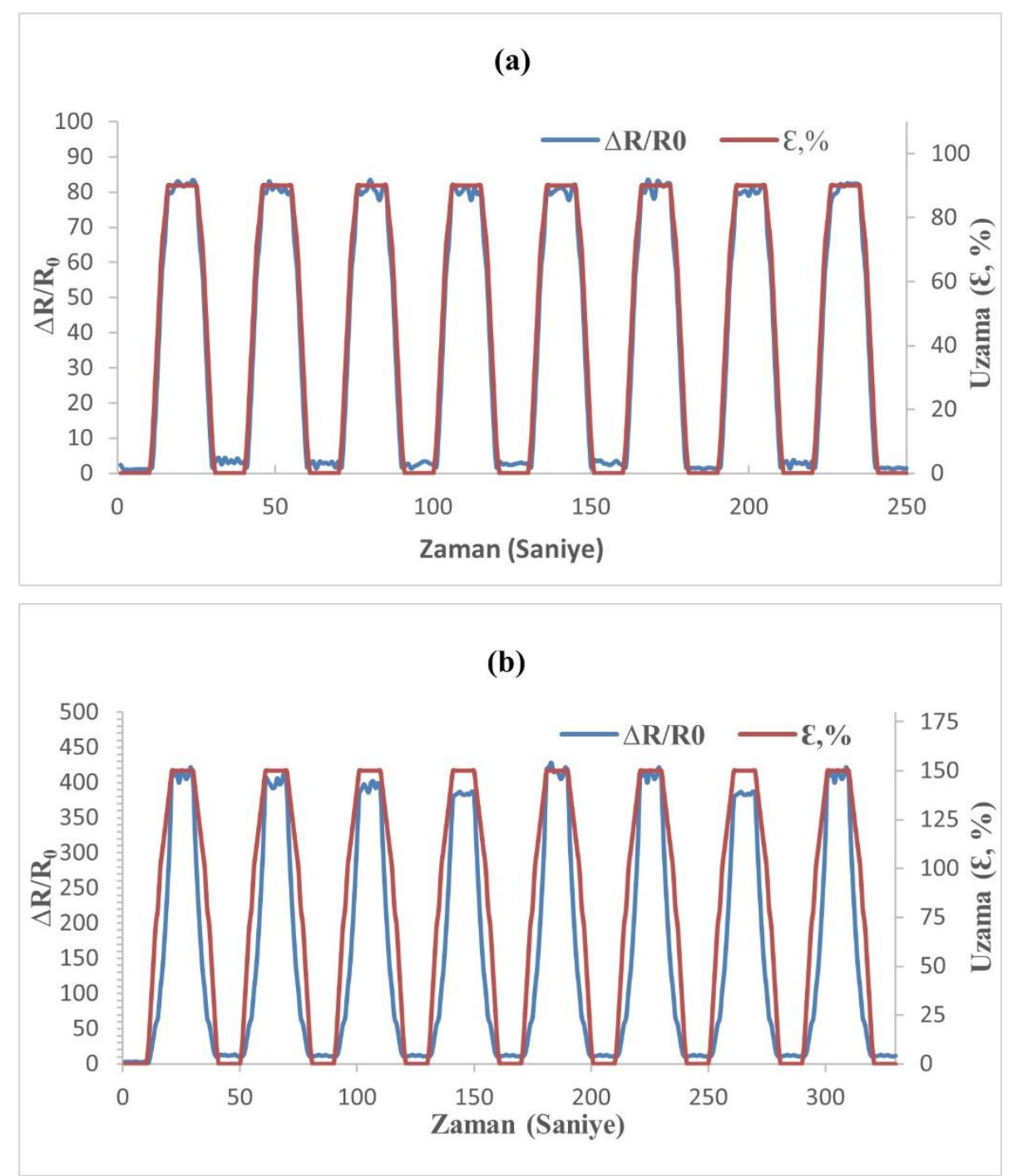

Şekil 8. (a) \%90 ve (b) \%150 arasındaki tekrarl yükleme/boşaltma testleri için ağırlıkça \%2,92 oranında ECN'nin piezodirenç davranışı 
Denklem (4) kullanılarak, ağırlıkça \%2.92 MW-CNT dolgulu nanokompozitlerin ölçüm faktörü birinci bölge için yaklaşık 90 ve ikinci bölge için yaklaşık 270 olarak ölçülmüştür. Şekil 5'de sunulan statik ölçümlerle uyumlu olarak, daha yüksek bir uzama seviyelerinde (ikinci bölge) daha büyük direnç değişimleri elde edilmiştir. Ölçülen direnç değişimleri, nanokompozitin elastik deformasyonlara karşılık her iki yüzdesel uzama seviyesi için sekiz çevrim boyunca tekrarlanabilir ve tersine çevrilebilir olduğu gösterilmiştir. Bu sonuçlar, nanokompozit numunelerinin uzamaya bağlı hassas gerilim sensörleri olarak kullanılabileceğini göstermiş̧tir.

\section{Sonuç}

Farklı dolgu oranlarında MW-CNT'lerin elastomer malzemeler ile birleştirilmesi sonucunda elde edilen nanokompozit numunelerinin mekanik zorlamalara bağlı şekil değişikliklerinden kaynaklanan uzamaları algılama performansları araştırılmıştır. $\mathrm{Bu}$ tür nanokompozitlerin sensör olarak kullanılmasının avantajları, esneklikleri, üretim kolaylığı ve dikkat çekici hassasiyetleridir. Hazırlanan numuneler üzerinde yapılan yüklemeye bağlı uzamanın algılanması için piezodirenç testlerinde aşağıdaki sonuçlar elde edilmiştir:

1. İletken dolgu maddelerinin polimer malzemelere dâhil edilmesiyle elde edilen nanokompozitler elektronik uygulamalar için büyük potansiyele sahiptirler. MWCNT'nin kademeli olarak eklenmesi ile elektriksel iletkenliği önce yavaş bir şekilde ardından keskin bir şekilde artış göstermiştir.

2. Ağırlıkça \% 0.3-1.19 arasında elektriksel iletkenlik çok düşük, neredeyse yalıtkan bir malzeme gibi davranmaktadır. MW-CNT miktarı arttıkça birbirine bağlanan bazı iletken kümeler kademeli olarak oluşmaktadır.

3. Ağırlıkça \%2.06 ulaşıldığında MW-CNT'ler arasında tam bir iletken yol olmamasına rağmen, iletken dolgular arasındaki tünelleme etkisi sayesinde elektriksel iletkenlik kademeli olarak artmaya başlamıştır.

4. Ağırlıkça \%2.06 ile 2.92 arasında MW-CNT'lerin miktarı artması ile nanokompozitin elektriksel iletkenliği dikkat çekici bir şekilde artmıştır. Bu dolgu aralığında ECN'lerin iletkenliği 6.97E-09 S/m'den $2.56 \quad \mathrm{~S} / \mathrm{m}^{\prime}$ ye aniden değişmiştir. Nanokompozit numunesindeki süzülme eşiği bu dolgu aralığında gerçekleşmiştir.

5. Ağırlıkça \%3.48'den 5.88'e arttırılmasıyla, ECN'lerin iletkenlikleri 4.44E+02 ile 5.56E+03 şeklinde değişmiş olup neredeyse iletken bir malzeme gibi davranmışlardır.

6. Ağırlıkça \%0.3 ve \%1.19 oranında MW-CNT içeren nanokompozitler yalıtkan özelliklere sahip olup piezodavranış sergilemezler.

7. Süzülme eşiği etrafında dolgu içeriğine sahip nanokompozitler (\%2.06 , \% 2.92) için uzamanın bir fonksiyonu olarak piezodirenç tepkisi doğrusal olmayan bir davranış ortaya koyar. $\mathrm{Bu}$ numunelerin piezodirenç davranışı kritik bir uzama seviyesine kadar doğrusal olup sonrasında üstel olarak değişir. Süzülme eşiği etrafında dolgu içeren nanokompozitler için kritik yüzde uzama değeri \%90 civarında tanımlanmıştır.

8. Ağırlıkça $\% 3.48$ dolgu oranının üzerindeki nanokompozitlerde iletken şebekeyi yok etmek için nispeten daha yüksek yüzdesel uzama değerlerine ihtiyaç olduğu tespit edilmiş olup \%300 uzama değerine kadar algılanabilmiştir.
9. Ağırlıkça \%2.92 MW-CNT içeren ECN'nin \%100'lik bir uzama seviyesi için yaklaşık 105 birimlik bir ölçüm faktörü göstermiştir. MW-CNT miktarı süzülme eşiğinden uzaklaştıkça, ölçüm faktörünün de büyük ölçüde azaldığı tespit edilmiştir.

10. Ağırlıkça \%2.92 oranında MW-CNT içerene nanokompozitlere yapılan tekrarlı testlerde ölçülen direnç değişimleri, nanokompozitin elastik deformasyonlara karşılık $\% 90$ ve $\% 150$ oranındaki uzama seviyeleri için tekrarlanabilir ve tersine çevrilebilir olduğu görülmüş olup, uzamaya bağlı hassas gerilim sensörleri olarak kullanılabileceğini görülmüştür.

\section{Teşekkür}

Yapılan çalışmalarda laboratuvar olanaklarından yararlanmamızı sağlayan Pega Otomotiv A.Ş. firmasına teşekkür ederim.

\section{Kaynakça}

Shivashankar P., Gopalakrishnan S. (2020). Review on the use of piezoelectric materials for active vibration, noise, and flow control. Smart Materials and Structures, 29(5), 053001 .

Kang I., Schulz M.J., Kim J.H., Shanov V., Shi D. (2006). A carbon nanotube strain sensor for structural health monitoring. Smart Materials and Structures, 15(3), 737-748.

Xu, T., Qiu, Q., Lu, S., Ma, K., \& Wang, X. (2019). Multidirection health monitoring with carbon nanotube film strain sensor. International Journal of Distributed Sensor Networks, 15(2).

Qureshi, E.M., Shen, X., \& Chang, L. (2015). A Low Frequency Vibration Control by Synchronized Switching on Negative Capacitance and Voltage Sources. International Journal of Control and Automation, 8(6), 121-138.

Shihong Xu. \& Fan, Zeng \& Li, Chengwei \& Wang, Peng \& Sammed, Khan \& Pan, Lujun. (2019). Investigation of strain sensing mechanisms on the ultra-thin carbon nanotube networks with different densities. Carbon. 155, 421-431.

Kanoun, O., Bouhamed, A., Ramalingame, R., Bautista-Quijano, J. R., Rajendran, D., \& Al-Hamry, A. (2021). Review on Conductive Polymer/CNTs Nanocomposites Based Flexible and Stretchable Strain and Pressure Sensors. Sensors (Basel, Switzerland), 21(2), 341.

Shimada, K., \& Saga, N. (2017). Development of a Hybrid Piezo Natural Rubber Piezoelectricity and Piezoresistivity Sensor with Magnetic Clusters Made by Electric and Magnetic Field Assistance and Filling with Magnetic Compound Fluid. Sensors (Basel, Switzerland), 17(2), 346.

Wang, X., Wang, S. \& Chung, D.D.L. (1999). Sensing damage in carbon fiber and its polymer-matrix and carbon-matrix composites by electrical resistance measurement. Journal of Materials Science 34(11), 2703-2713.

Kim, K. \& Tia, Mang \& Greene, J.(2017). Performance Characteristics of Fiber-Optic Strain Sensors as Compared With Electrical Resistance and Vibrating Wire Strain Gauges. Journal of Testing and Evaluation. 45(6), 20160281.

Avilés, F., May-Pat, A., Canché-Escamilla, G., RodríguezUicab, O., Ku-Herrera, J. J., Duarte-Aranda, S., UribeCalderon, J., Gonzalez-Chi, P. I., Arronche, L., \& La Saponara, V. (2016). Influence of carbon nanotube on the 
piezoresistive behavior of multiwall carbon nanotube/polymer composites. Journal of Intelligent Material Systems and Structures, 27(1), 92-103.

Chen W., Li F., Ooi P.C., Ye Y., Kim T.W., Guo T. (2016). Room temperature $\mathrm{pH}$-dependent ammonia gas sensors using graphene quantum dots. Sensors Actuators B: Chemical, 222, 763-768.

Alamusi, Hu, N., Fukunaga, H., Atobe, S., Liu, Y., \& Li, J. (2011). Piezoresistive strain sensors made from carbon nanotubes based polymer nanocomposites. Sensors (Basel, Switzerland), 11(11), 10691-10723.

Oliva-Avilés A., Avilés F., Sosa V. (2011). Electrical and piezoresistive properties of multi-walled carbon nanotube/polymer composite films aligned by anelectric field. Carbon, 49(9), 2989-2997.

Wichmann M.H.G., Buschhorn S.T., Gehrmann, J., Schulte, K.(2009). Piezoresistive response of epoxy composites with carbon nanoparticles under tensile load. Physical Review B, 80(24), 245437.

Kim Y.J., Cha J.Y., Ham H., Huh H., So D.S., Kang I. (2011). Preparation of piezoresistive nano smart hybrid material based on graphene, Current Applied Physics, 11(1), 350S352.

Meeuw H., Viets C., Liebig W., Schulte K., Fiedler B. (2016). Morphological influence of carbon nanofillers on the piezoresistive response of carbon nanoparticle/epoxy composites under mechanical load. European Polymer Journal, 85, 198-210.

Yazıcı M., Kapucu OA., Kasım H., Can Y. (2017). Experimental Investigation on Fatigue Life of Cord-Rubber Composites. Avrupa Bilim ve Teknoloji Dergisi, Ejosat Aralık Özel Sayı, 90,16-21

Santos A., Amorim L., Nunes J., Rocha L., Silva A.F., Viana, J.(2019). Aligned carbon nanotube based sensors for strain sensing applications. Sensors and Actuators A-physical, 289, 157-164.

Spinelli G., Lamberti P., Tucci V., Vertuccio L., Guadagno L. (2018). Experimental and theoretical study on piezoresistive properties of a structural resin reinforced with carbon nanotubes for strain sensing and damage monitoring. Composites Part B-engineering, 145, 90-99.

Yin, G., Hu, N., Karube, Y., Liu, Y., Li, Y., \& Fukunaga, H. (2011). A carbon nanotube/polymer strain sensor with linear and anti-symmetric piezoresistivity. Journal of Composite Materials, 45(12), 1315-1323.

Bokobza, L. (2012). Multiwall carbon nanotube-filled natural rubber: electrical and Mechanical Properties. Express Polymer Letters. 6(3), 213-223.

Qingliang He., Yuan T., Zhang X., Guo S., Liu J., Liu J.,Liu X., Sun L., Wei S., Guo Z. (2014). Heavy duty piezoresistivity induced strain sensing natural rubber/carbon black nanocomposites reinforced with different carbon nanofillers. Materials Research Express, 1(3), 035029.

Chen L., Chen G., Lu L. (2007). Piezoresistive behavior study on finger sensing silicone rubber/graphite nanosheet nanocomposites, Advanced Functional Materials, 17(6), 898-904.

Wang P., Geng S., Ding T. (2010). Effects of carboxyl radical on electrical resistance ofmulti-walled carbon nanotube filled silicone rubber composite underpressure. Composite Science and Technology, 70(10), 1571-1573.

Gao L., Chou T.W., Thostenson E.T., Zhang Z., Coulaud M. (2011). In situ sensing ofimpact damage in epoxy/glass fiber composites using percolating carbonnanotube networks. Carbon, 49(10), 3382-3385.

Zhang, Xiang-Wu \& Pan, yi \& Yi, Xiaosu. (2000). Time dependence of piezoresistance for the conductor-filled polymer composites. Journal of Polymer Science Part B: Polymer Physics. 38(21), 2739 - 2749.

Wang L., Ding T. H., Wang P. (2009). Influence of carbon black concentration on piezoresistivity for carbon-black-filled silicone rubber composite. Carbon, 47(14), 3151-3157.

Knite M., Teteris V., Kiploka A., Kaupuzs J. (2004). Polyisoprene-carbon black nanocomposites as tensile strain and pressure sensor materials. Sensors and Actuators A: Physical, 110(1-3), 142-149.

Chervanyov A.I.,Selvan N.T., Eshwaran S.B., Das A., Stöckelhuber K.W., Wießner S., Pötschke P.,. Nando G.B, Heinrich G. (2016). Piezoresistive natural rubber-multiwall carbon nanotube nanocomposite for sensor applications. Sensors and Actuators A: Physical, 239, 102-113.

Peng Z., Feng C., Luo Y., Li Y., Kong L. (2010). Selfassembled natural rubber/multi-walled carbon nanotube composites using latex compounding techniques. Carbon, 48(15), 4497-4503.

Simmons J.G. (1963). Electric tunnel effect between dissimilar electrodes separated by a thin insulating film. Journal of Applied Physics, 34(9), 2581-2590.

Rahman R., Servati P. (2012). Effects of inter-tube distance and alignment on tunnelling resistance and strain sensitivity of nanotube/polymer composite films. Nanotechnology, 23(5), 055703.

Bauhofer, W.; Kovacs, J.Z. (2009). A review and analysis of electrical percolation in carbon nanotube polymer composites. Composite Science and Technology, 69(10), 1486-1498.

Perets Y.S., Lazarenko O., Sivoloshsky O.A., Vovchenko L., Matzui L. (2020). Percolation characteristics of multipolymer composites with different ratios of nanocarbon fillers. Molecular Crystals and Liquid Crystals, 699(1), 97110

Chen J., Yan L. (2018). Effect of Carbon Nanotube Aspect Ratio on the Thermal and Electrical Properties of Epoxy Nanocomposites. Fullerenes, Nanotubes and Carbon Nanostructures, 26(11), 697-704.

Chanklin W., Laowongkotr J., Chibante L.P. (2018). Electrical property validation of percolation modeling in different polymer structures of carbon-based nanocomposites. Materials today Communications, 17, 153160.

Hu N., Masuda Z., Yan C., Yamamoto G., Fukunaga H., Hashida T. (2008). The electrical properties of polymer nanocomposites with carbon nanotube fillers. Nanotechnology, 19(21), 215701.

Sánchez-Romate X.F., Jiménez-Suárez A., Sánchez M., Güemes A., Ureña A. (2016). Novel approach to percolation threshold on electrical conductivity of carbon nanotube reinforced nanocomposites. RSC Advances, 6(49), 4341843428.

Yang W., Ke K., Yue L., Shao H., Yang M., Manas-Zloczower I.(2021). Boosting Electrical and Piezoresistive Properties of Polymer Nanocomposites via Hybrid Carbon Fillers: A Review. Carbon. 173, 1020-104.

Yazdani-Pedram M., Aguilar-Bolados H., Contreras-Cid A., López-Manchado M.A., May-Pat A., Avilés F.(2017). Influence of the morphology of carbon nanostructures on the 
piezoresistivity of hybrid natural rubber nanocomposites. Composites Part B-engineering, 109, 147154.

Balberg I. (1987). Tunneling and nonuniversal conductivity in composite materials. Phys. Rev. Lett. 59(12), 1305-1308.

Meguid S., Alian A. (2019). Multiscale modeling of the coupled electromechanical behavior of multifunctional nanocomposites. Composite Structures, 208, 826-835.

Das, A., Natarajan T.S., Eshwaran S., Stöckelhuber K.W., Wießner S., Pötschke P., Heinrich G. (2017). Strong Strain Sensing Performance of Natural Rubber Nanocomposites. ACS applied materials \& interfaces, 9(5), 4860-4872.

Xu W., Allen M. (2013). Deformable Strain Sensors Based on Patterned MWCNTs/ Polydimethylsiloxane Composites. Journal of Polymer Science Part B, 51(20), 1505-1512.

Kasım H., Demir, B. (2021). Investigation of electrical properties of hybrid nanocomposites containing different fillers on pressure sensor applications under different loading. Journal of Composite Materials.

Kalantari M., Dargahi J., Kövecses J., Mardasi M.G., Nouri, S. (2012). A New Approach for Modeling Piezoresistive Force Sensors Based on Semiconductive Polymer Composites. IEEE/ASME Transactions on Mechatronics, 17(3), 572-581. 